
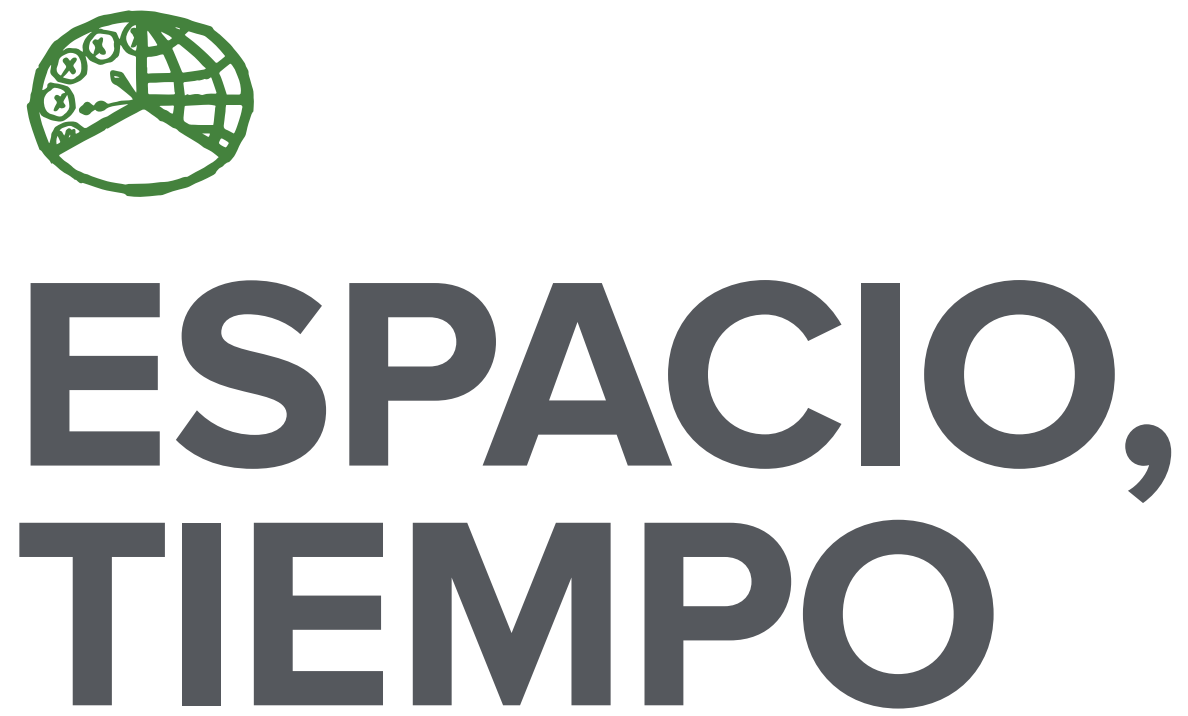

AÑO 2017

ISSN 1130-2968

E-ISSN 2340-146X
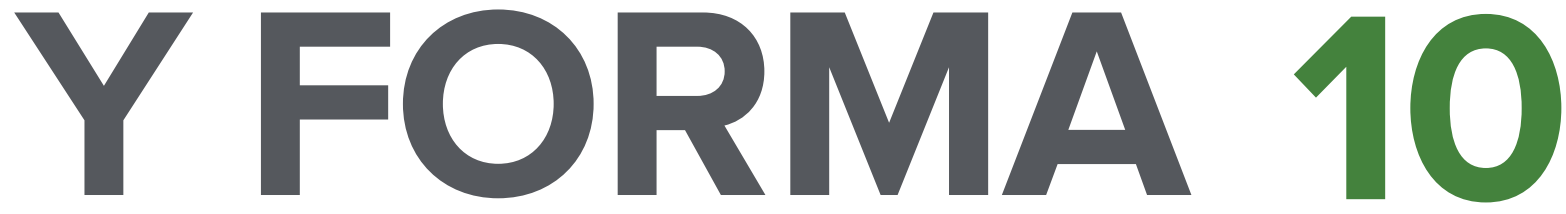

SERIE VI GEOGRAFÍA

REVISTA DE LA FACULTAD DE GEOGRAFÍA E HISTORIA 


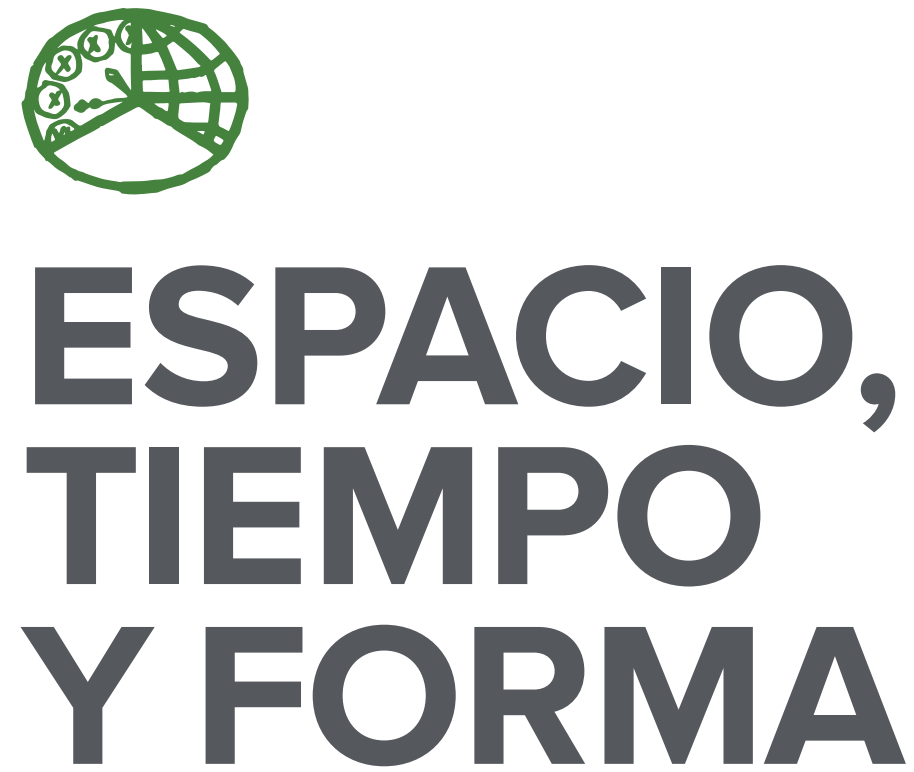

AÑO 2017

ISSN 1130-2968

E-ISSN 2340-146X

SERIE VI GEOGRAFÍA

REVISTA DE LA FACULTAD DE GEOGRAFİA E HISTORIA

DOI: http://dx.doi.org/10.5944/etfvi.10.2017

\section{UกED}

UNIVERSIDAD NACIONAL DE EDUCACIÓN A DISTANCIA 
La revista Espacio, Tiempo y Forma (siglas recomendadas: ETF), de la Facultad de Geografía e Historia de la UNED, que inició su publicación el año 1988, está organizada de la siguiente forma:

$$
\begin{aligned}
& \text { SERIE I - Prehistoria y Arqueología } \\
& \text { SERIE II - Historia Antigua } \\
& \text { SERIE III - Historia Medieval } \\
& \text { SERIE IV - Historia Moderna } \\
& \text { SERIE V - Historia Contemporánea } \\
& \text { SERIE VI - Geografía } \\
& \text { SERIE VII - Historia del Arte }
\end{aligned}
$$

Excepcionalmente, algunos volúmenes del año 1988 atienden a la siguiente numeración:

$$
\begin{aligned}
& \mathrm{N}^{\circ} 1 \text { - Historia Contemporánea } \\
& \mathrm{N}^{\circ} 2 \text { - Historia del Arte } \\
& \mathrm{N}^{\circ} 3 \text { - Geografía } \\
& \mathrm{N} .^{\circ} 4 \text { - Historia Moderna }
\end{aligned}
$$

ETF no se solidariza necesariamente con las opiniones expresadas por los autores.

\author{
UNIVERSIDAD NACIONAL DE EDUCACIÓN A DISTANCIA \\ Madrid, 2017 \\ SERIE VI · GEOGRAFÍA N. ${ }^{\circ} 10,2017$ \\ ISSN $1130-2968 \cdot$ E-ISSN 2340-146x \\ DEPÓSITO LEGAL \\ $M-21.037-1988$ \\ URL \\ ETF VI - GEOGRAFÍA $\cdot h t t p: / / r e v i s t a s . u n e d . e s / i n d e x . p h p / E T F V I$ \\ DISEÑO Y COMPOSICIÓN \\ Carmen Chincoa Gallardo · http://www.laurisilva.net/cch \\ Impreso en España · Printed in Spain
}


IMÁGENES Y PALABRAS .

PICTURES AND WORDS 



\title{
EL MUSEO HIDRÁULICO DE MURCIA: UN ESPACIO INFRAUTILIZADO
}

\section{THE HYDRAULIC MUSEUM OF MURCIA: AN INFRAUTILIZED SPACE}

\author{
Gregorio Castejón Porcel \& Gregorio Canales Martínez
}

Recepción: 23/01/2017 · Aceptación: 15/03/2017

DOI: http://dx.doi.org/10.5944/etfvi.10.2017.18622

La Región de Murcia cuenta con un producto turístico diversificado adaptado a cada uno de los recursos propios de su territorio. En concreto, la ciudad de Murcia ha potenciado el turismo cultural como estrategia para dar a conocer la peculiaridad del conjunto urbano; fruto de estas iniciativas, desde la propia administración, se han promovido en las últimas décadas una serie de nuevos museos. Estos tienen como finalidad dar a conocer el contexto histórico de la fundación y evolución de la urbe, así como la riqueza patrimonial que ha ido aglutinando con el paso de los siglos. Las citadas infraestructuras museísticas se han desarrollado a la par que ciertos equipamientos públicos de carácter complementario que, en conjunto, contribuyen a reforzar todavía más la proyección turística de la capital.

Entre estas actuaciones cabe destacar la recuperación en I989 de un antiguo molino harinero accionado por las aguas del Segura y edificado bajo el patrocinio del murciano José Moñino y Redondo, primer conde de Floridablanca, ministro ilustrado bajo el reinado de Carlos III quién, entre I777-I792, estuvo al frente de importantes secretarías como la de Estado y la de Gracia y Justicia. En el apogeo de su carrera política mejoró notablemente su ciudad natal dado que promovió en I785 la construcción de los Molinos Nuevos, según la propuesta firmada un año antes por Manuel Serrano. El proyecto concebido por éste consistía en demoler dos pares de molinos existentes en ambas riberas del río, antes y después del Puente de los Peligros, y sustituirlos por una única instalación que albergara 47 piedras en un inmueble dispuesto longitudinalmente en la margen derecha. Éste se planteó en el emplazamiento que ocupaba otro anterior datado ya en el siglo XIV (Molino del Batán) y que, junto con los tres restantes, se disponían perpendicularmente a la corriente obstaculizando su circulación en momentos de avenida. La riada acaecida en I784 motivó la mencionada planificación que resultó excesivamente ambiciosa ya que finalmente de lo previsto sólo se le pudo construir una veintena de ruedas,

1. Grupo de Investigación de Estudios Críticos y América Latina (GIECRYAL). Departamento de Geografía Humana. Universidad de Alicante; <gregorio.castejon@ua.es>,<gregorio.canales@ua.es>. 


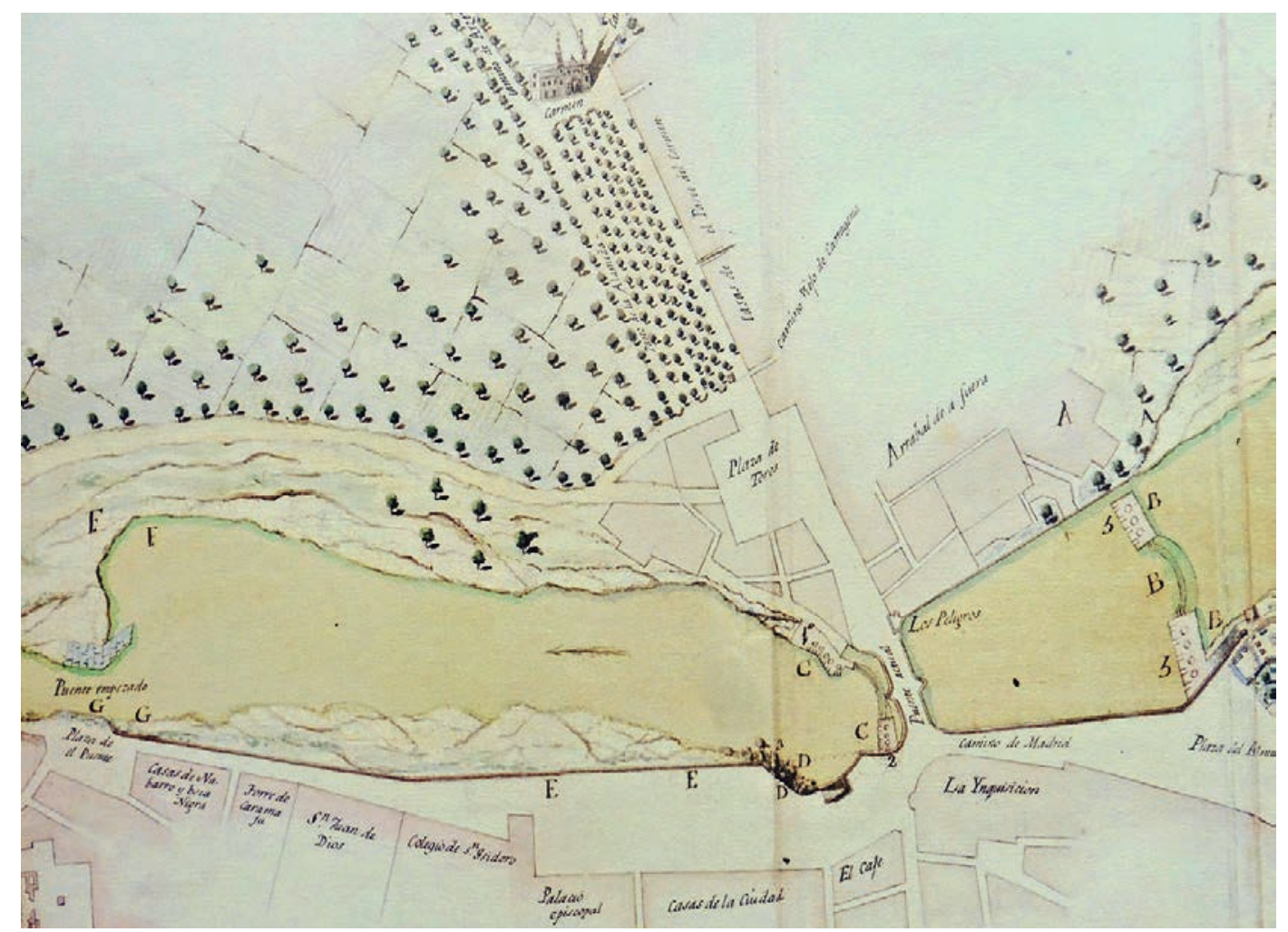

FIG. 1. PLANO ELABORADO EN 1784 POR MANUEL SERRANO, DONDE SEÑALA LOS MOLINOS HIDRÁULICOS EXISTENTES AGUAS ARRIBA Y ABAJO DEL PUENTE DE LOS PELIGROS EN MURCIA. (Fuente: González y Calvo, 2005).

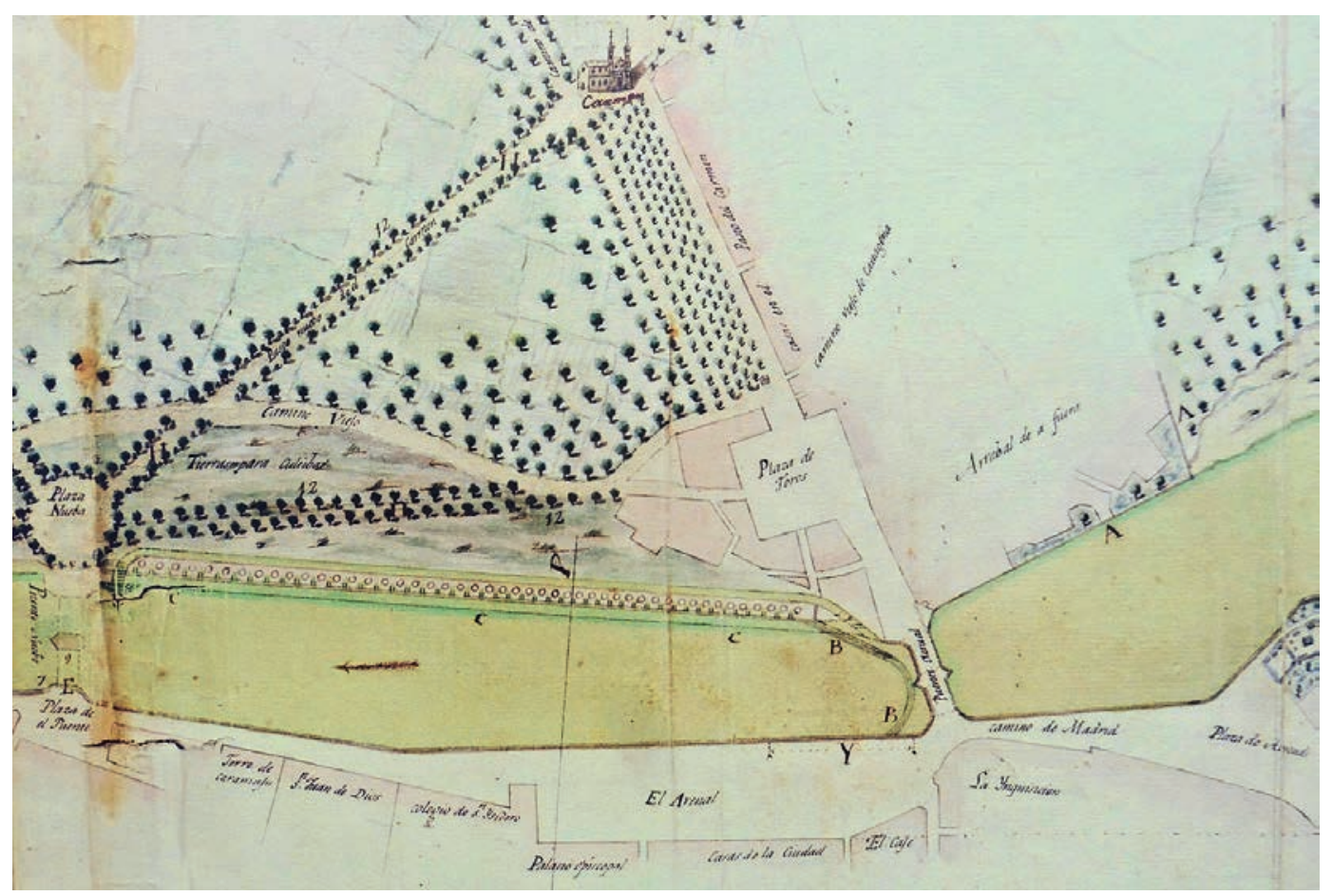

FIG. 2. PROYECTO DEL NUEVO MOLINO HARINERO DISEÑADO POR MANUEL SERRANO EN 1784 PARA INSTALAR EN SUS INICIOS 47 RUEDAS. (Fuente: González y Calvo, 2005). 
ampliándose posteriormente a veinticuatro en I808. El molino estuvo en funcionamiento hasta la segunda mitad del siglo pasado y es el que con ligeras modificaciones ha llegado hasta nuestros días adaptado como museo.

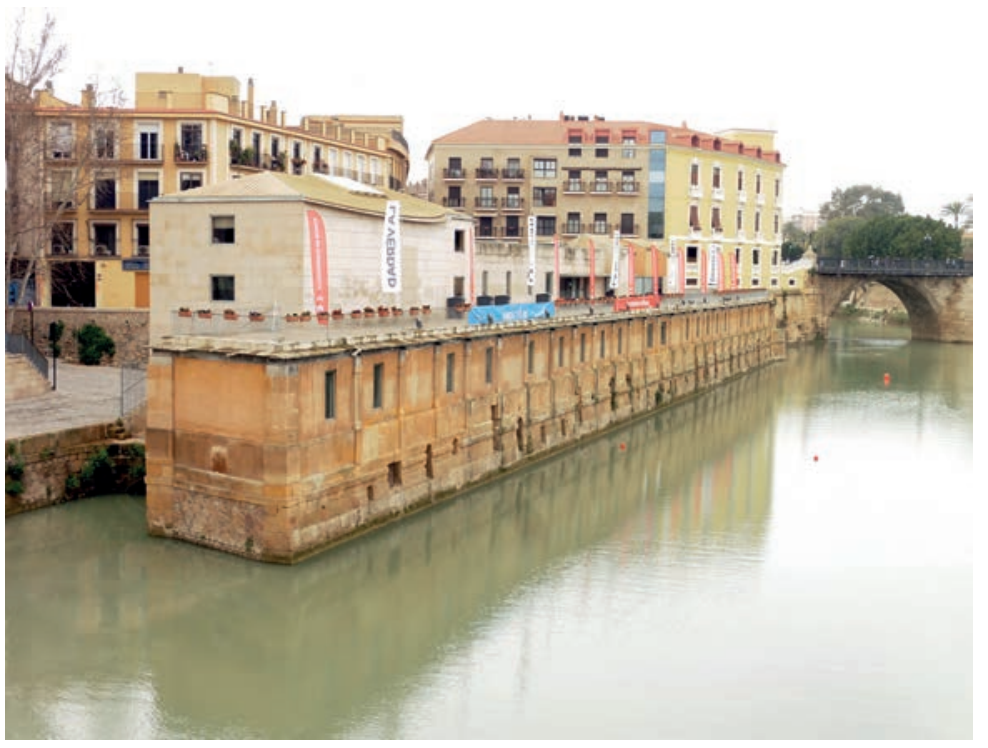

FIG. 3. VISTA EXTERIOR DEL MUSEO HIDRÁULICO MOLINOS DEL RÍO SEGURA emplazado longitudinalmente al curso del río. (Fotografía, G. Canales).

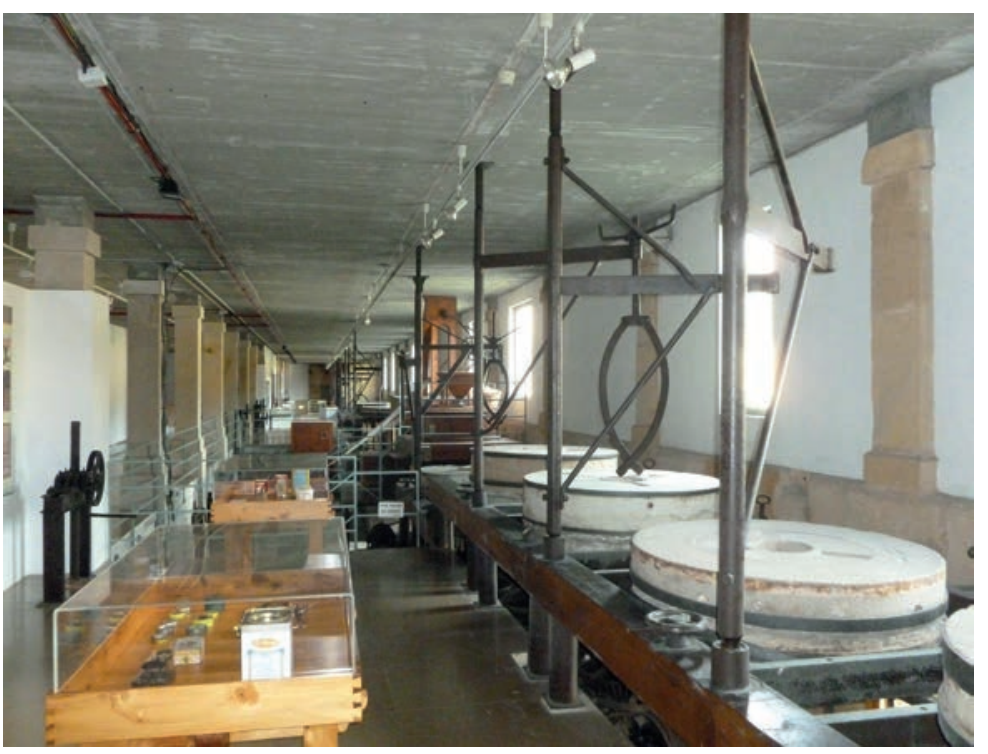

FIG. 4. PERSPECTIVA INTERIOR DE LA BATERÍA DE 24 PIEDRAS DESTINADAS A LA MOLIENDA. (Fotografía, G. Castejón).

El Museo Hidráulico está emplazado en pleno centro de la ciudad de Murcia, en la orilla opuesta a la Glorieta de España donde se encuentra el Ayuntamiento; se accede a él atravesando el Puente Viejo o de Los Peligros cuya fábrica de sillares es de la misma centuria aunque levantado casi medio siglo antes reemplazando a otro que quedó igualmente destruido por la riada de San García en I7or. El citado viaducto, emplazado en el Camino Viejo a Cartagena, conectaba la ciudad amurallada con la Huerta sur y dio origen en el XVIII a una ampliación urbana tras la mota del río, el Barrio del Carmen, originando un primer espacio público de planta ortogonal -la Plaza de Camachos- desde la que se desciende al edificio molinar. La protección divina frente a los desastres naturales y más concretamente el riesgo inundación, se hace patente en este lugar mediante la presencia en uno de los edificios junto al puente de una gran hornacina de estilo neoclásico de dos pisos de altura que alberga en su interior una talla de la virgen en cuyo entablamento se lee «Salus in Periculis».

El entorno urbano en el que se inserta el museo representa por sí mismo un importante conjunto patrimonial vinculado a la cultura del agua, no sólo de la ciudad sino de la propia comunidad autónoma. Si bien, la instalación museística está centrada exclusivamente en la importancia que para la economía de la zona tuvo la industria molinera con un discurso expositivo mediante paneles y el apoyo de varias maquetas que dan a conocer la historia y evolución tecnológica de los molinos harineros desde la prehistoria hasta la actualidad. El inmueble reúne, además de un auditorio (donde se proyecta un video alusivo a la huerta, al río Segura y a la utilización de la energía hidráulica como fuerza motriz que acciona el engranaje 


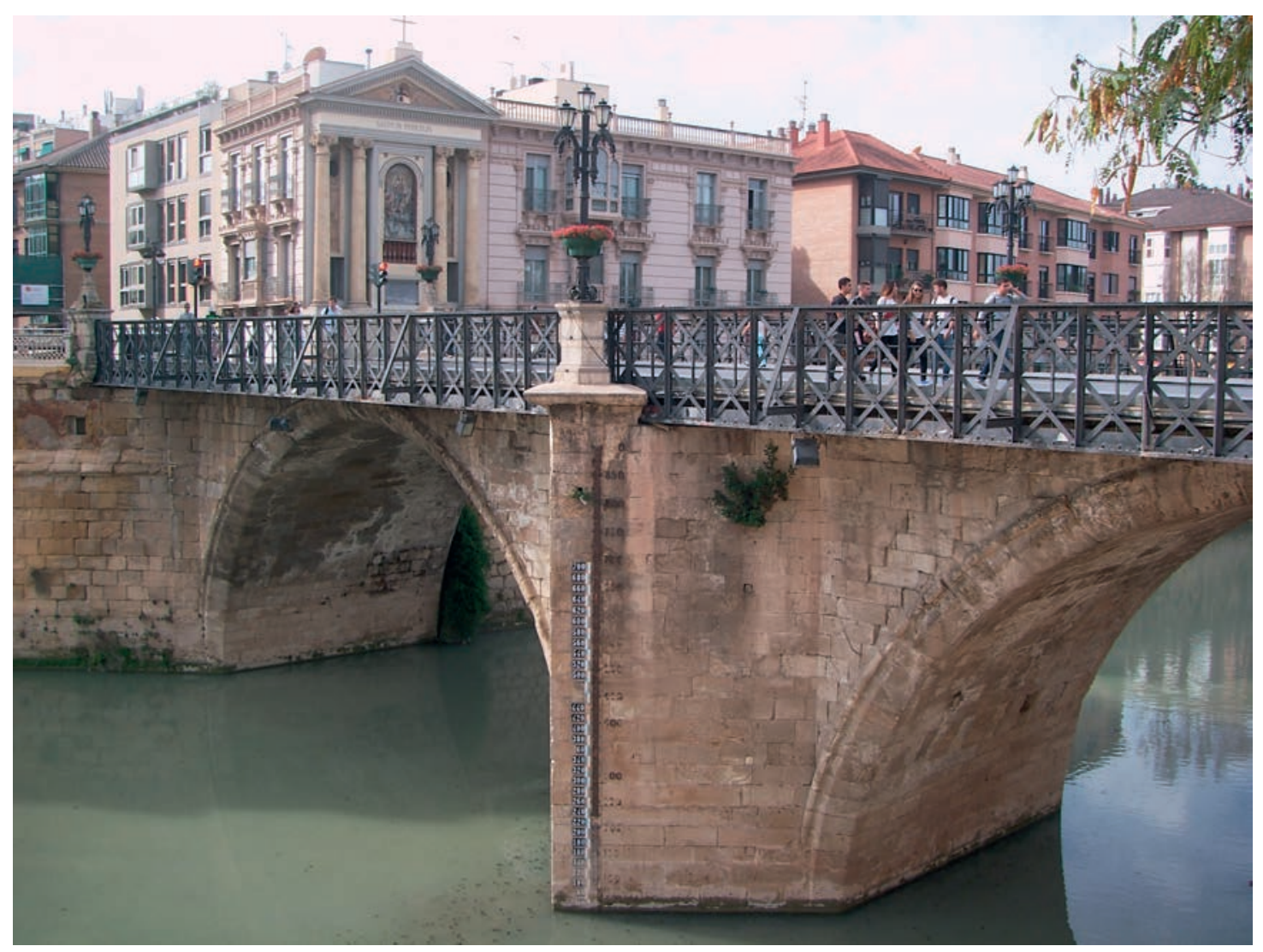

FIG. 5. PUENTE VIEJO DEL SIGLO XVIII Y TRAS ÉL LA HORNACINA QUE ALBERGA LA VIRGEN DE LOS PELIGROS, protectora contra el secular riesgo de inundación del río segura. (Fotografía: G. Canales).

que mueve las piedras), tres salas destinadas a exposiciones temporales; la de mayor tamaño situada en las antiguas cuadras y conocida con el nombre de Caballeriza, edificio anexo que ocupa una superficie de $150 \mathrm{~m}^{2}$. Estas estancias mantienen una programación anual centrada principalmente en muestras fotográficas de diverso tipo y alejadas del contenido específico del señalado museo.

Se trata, por consiguiente, de una utilización poco adecuada a los fines para los que deberían ser destinados estos espacios ya que, a nuestro juicio, sería deseable que todos ellos mantuvieran un montaje narrativo homogéneo y relacionado con la cultura del agua y el patrimonio asociado a ella, bien de la ciudad de Murcia o de la comunidad autónoma. La capital alberga tres grandes hitos de relevancia y proyección relacionados con el río Segura y su ancestral espacio regado, la Huerta, como son: a) el Plan de Defensa contra Avenidas en la Cuenca del Río Segura aprobado por el Estado en 1987 tras la riada de carácter extraordinario sufrida en octubre de ese año, que ha dejado como resultado el nuevo encauzamiento del Segura desde la Contraparada, al inicio de la Huerta de Murcia, hasta su desembocadura en el sur alicantino, con una reducción longitudinal del río de un 26,1\% mediante el corte de meandros, siendo ésta una de las veintisiete actuaciones contempladas en él; b) la declaración del Consejo de Hombres Buenos de la Huerta de Murcia como Patrimonio Cultural Inmaterial de la Humanidad por la UNESCO en 2009, institución encargada 


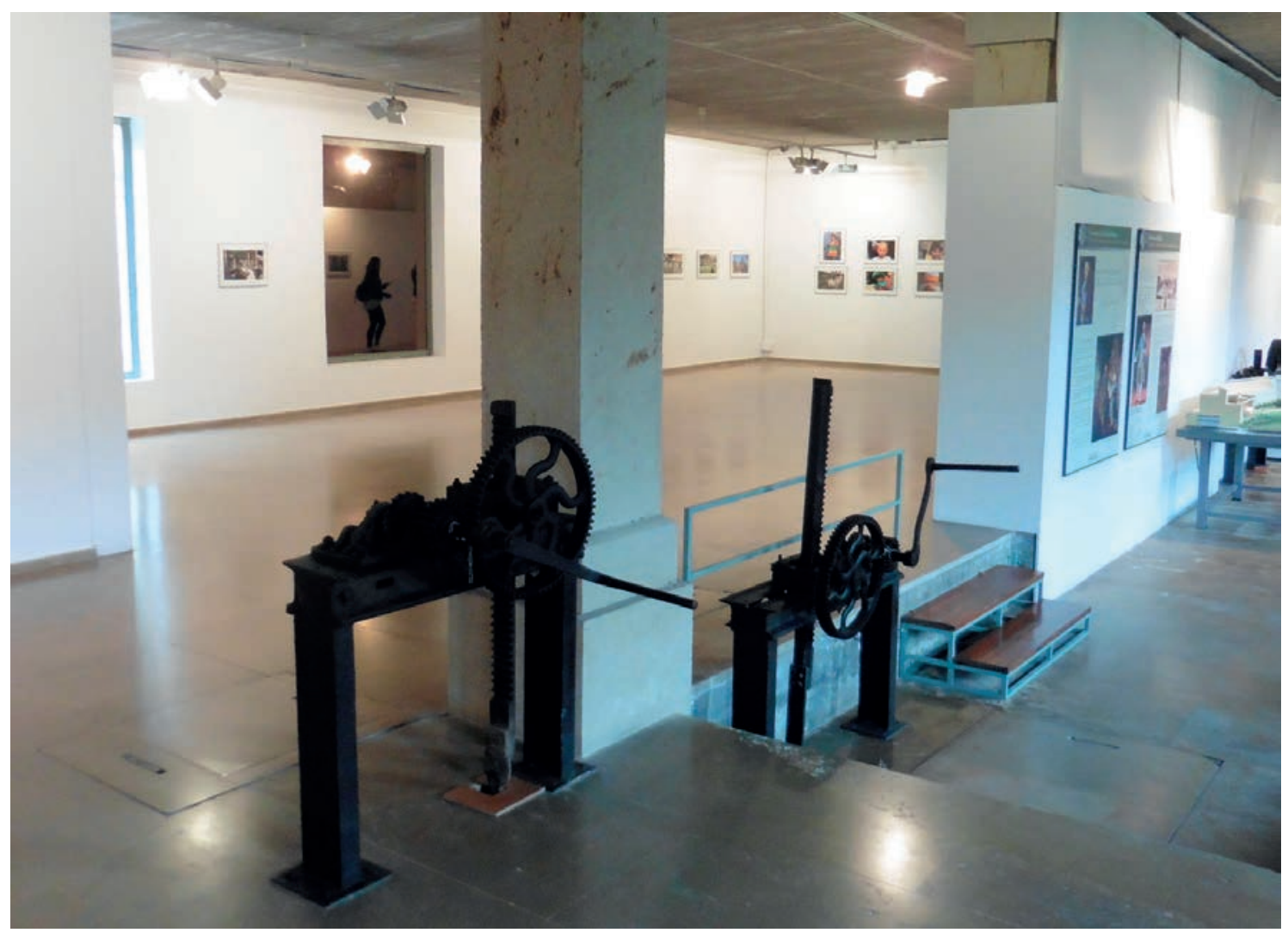

FIG. 6. DETALLE DE UNA DE LAS TRES SALAS DE EXPOSICIONES CON QUE CUENTA EL ACTUAL MUSEO UBICADO EN EL ANTiguo COMPLejo molinar. (Fotografía: G. Castejón).

de velar por la correcta distribución de los caudales en el regadío histórico; y, por último, c) el reconocimiento del Bando de la Huerta como Fiesta de Interés Turístico Internacional, hecho que tuvo lugar en 2012 y cuya manifestación lúdico-festiva reconoce el significado y atractivo que para el turismo tiene esta manifestación que se viene celebrando desde I85I.

Además de estos tres grandes eventos, la Región de Murcia presenta en su conjunto un importante patrimonio hidráulico parte del cual se encuentra protegido, al estar inventariados un total der66 elementos catalogados como Bien de Interés Cultural (B.I.C.), amén de otros 233 reconocidos por su importancia local como Bien Catalogado por su Relevancia Cultural (B.C.R.C.). Pese a ello, no existe un centro de interpretación o memorial que aborde la repercusión territorial y socioeconómica que las infraestructuras relacionadas con el agua han tenido en un enclave tan árido como el murciano. En este sentido, la comunidad autónoma es señera a nivel nacional por la reivindicación permanente que hace del agua, representada, tiempo atrás, en el eslogan de «Agua para todos», frase ciertamente imprecisa y partidista utilizada durante el periodo del auge inmobiliario que precedió a la actual crisis económica. Hoy día, dicha consigna se ha sustituido por «El agua que nos une» cuando han surgido intereses que cuestionan la transferencia de caudales de unas cuencas hidrográficas a otras, en clara alusión al Trasvase Tajo-Segura, obra que ha tenido una honda repercusión en el desarrollo regional. 


\section{BIBLIOGRAFÍA}

Castejón Porcel, G.; Canales Martínez, G. (20i6): «El patrimonio hidráulico de la Región de Murcia y la necesidad de su puesta en valor mediante un Memorial sobre la Cultura del Agua». En García Marín, R. et al. (Eds.) XV Coloquio Ibérico de Geografía. Retos y tendencias de la Geografía Ibérica. Murcia, Universidad de Murcia, Asociación de Geógrafos Españoles y Asociación Portuguesa de Geografía, pp. 458-467.

González Castaño, J. Calvo García-Tornel, F. (2005): El Proyecto de canalización y ornato del río Segura a su paso por Murcia (I785). Murcia, Real Academia Alfonso X El Sabio. I6 pp. (Contiene reproducción facsímil de los 4 mapas, con sus correspondientes hojas explicativas, firmados por Manuel Serrano en I784 y aprobados un año después por el Conde de Floridablanca).

Hernández Franco, J. (I987-I989): «Floridablanca entre la reacción y la revolución (I787-I792)». Estudios románicos, vol. 6, Murcia, Universidad de Murcia, Servicio de Publicaciones, pp. I.659-I.67I.

Martínez Carrillo, M. ${ }^{a}$ LL. (2004): «Los Molinos del Río». Cuadernos de Patrimonio Histórico-Artístico de la Región de Murcia, 44, Murcia, Ayuntamiento de Murcia, Patrimonio S. XXI. 29 pp.

Martínez Carrillo, M. ${ }^{a}$ LL. y Martínez Martínez, M. (I993): Orígenes y expansión de los molinos hidráulicos en la ciudad y huerta de Murcia (siglos XIII-XV). Murcia, Ayuntamiento de Murcia. I25 pp.

Martínez Martínez, M. ${ }^{\mathrm{a}}$ (2014): Molinos de Allende. Antecedentes medievales del Museo Hidráulico de Murcia. Murcia, Ayuntamiento de Murcia. 156 pp.

Parrá lledó, I.; Riquelme Pacheco, A.; Rosa Barbero, A. (I99i): Molinos del río Segura: Los molinos nuevos. Murcia, Ayuntamiento de Murcia. I84 pp. 
PRESENTACIÓN · FOREWORD

\section{Artículos · Articles}

19

\section{ENRIQUe Alegre VICENTE}

Las nuevas localizaciones industriales en el Bajo Gállego (Zaragoza). Efectos en el paisaje desde la década de 1980 . The New Industrial Locations in the Bajo Gállego (Zaragoza). Effects on the Landscape from the Decade of 1980

45

José Antonio BarRa Martínez

La epidemia de ébola de África occidental: una visión desde la geografía de la salud · Ebola Epidemic in West Africa: A View From Health Geography Perspective

79

FERnANDO Collado Lozano

Refugios antiaéreos de la ciudad de Valencia: estudio, propuesta y desarrollo como paisajes culturales urbanos - Air-Raid Shelters of Valencia City: Study, Proposal and Development as Urban Cultural Landscapes

103 María luisa de LÁzaro y TORRes \& Rafael de Miguel González \& ISAAC BuZO SÁNCHEZ

El proyecto School on the Cloud: lecciones aprendidas Project: Lessons Learned

121

Nicolás García Galán

Territorios separados en España: origen y situación actual · Separate Te-

\section{5}

Natalia Martín Vaqueiro

Expedición de los hermanos Heuland a Chile y Perú . The Expedition of the Heuland Brothers to Chile and Peru

Marc Oliva \& Jesús Ruiz-Fernández \& Andrés Zarankin \& María Angélica Casnova-Katny \& Jordi NOFre

Propuesta de protección ambiental para un enclave libre de hielo de la Antártida Marítima (Punta Elefante, isla Livingston) - Proposal of Environmental Protection for an Ice-free Area in the Maritime Antarctic (Elephant Point, Livingston Island)
225

José Ramón SÁNCHEZ Holgado

El peñón de Salobreña. Pasado, presente y posibilidades de futuro

\section{The Rock of Salobreña. Past, Present and Future Possibilities}

25 Miguel Ángel SÁNCHEZ SÁNCHEZ

Marco teórico-referencial para la protección, gestión y ordenación del paisaje. El caso de la Región de Murcia . Theoretical-referential Framework for the Protection, Management and Landscape Management. The Case of the Region of Murcia

\section{Reseñas · Book Review}

283 ZÁrATE MARTín, Manuel Antonio (Director) 2016. Paisajes culturales a través de casos en España y América. Madrid, Universidad Nacional de Educación a Distancia. Serie Arte y Humanidades, 350 pp. ISBN 978-84-362-7000-6. (DARÍo CÉSAR SÁnCHEZ)

28 Bosque MAUREL, Joaquín (2012): España en el tercer milenio. Una imagen geográfica de una sociedad moderna y en cambio. Granada, Ediciones de la Universidad de Granada-Real Sociedad Geográfica, 256 pp. ISBN 978-84-338-5381-3. (ALEJANDRO GARCÍA FERRERO)

23 BRIz, Julián, KöHLER, Manfred, FELIPE, Isabel de (eds.) (2014): Green cities in the world. Progression, Innovation, Organization. Madrid Editorial Agrícola Española, Pronatur, World Green Infraestructure Network, 357 pp. ISBN 978-84-92928-30-9. (ALEJANDRO GARCía FERrERo)

299 DIJKSTRA, LEWIS, MASELAND, Jos (eds. y coords.) (2016): The State of European Union, United Nations Human Settlements Programme (UN-Habitat), 214 Pp. ISBN (Volume) 978-92-1-132717-5. (ALEJANDRO GARCíA FERRERO)

303 Serrano CAÑAdas, Enrique: Islas de hielo. Naturaleza, presencia humana y paisaje en las Islas Shetland del Sur, Antártida. Valladolid, Universidad de Valladolid, Secretariado de Publicaciones e Intercambio Editorial, 2008, 248 págs. ISBN 978-84-844-8468-4. (Jesús RUIZ-FERNÁNDEZ \& CRISTINA

\section{Imágenes y palabras · Pictures and Words}

314 Gregorio Castejón Porcel \& Gregorio Canales Martínez El museo hidráulico de Murcia: un espacio infrautilizado . The Hydraulic

\section{Síntesis de Tesis Doctorales · Summaries of Doctoral Thesis}

319 Ocio y turismo en el paisaje madrileño. Departamento de Geografía. Universidad Nacional de Educación a Distancia. Director: Manuel Antonio Zárate Martín. Fecha: 14 de noviembre de 2016. (AlEjANDRO GARCía FERRERO) 